\title{
A BIM-Based Conceptual Model to Manage Knowledge in Construction Design
}

\author{
Ahmed Al Sehrawy ${ }^{1}$ and Omar Amoudi ${ }^{2}$
}

1 School of Computing, Engineering and Built Environment, Glasgow Caledonian University, UK, ahmed.alsehrawy@gcu.ac.uk

2 Department of Built \& Natural Environment, Caledonian College of Engineering, Sultanate of Oman, omaramoudi@nu.edu.om

\begin{abstract}
Managing knowledge had always captured the attention of researchers, since Plato's epistemology till now, where it is seen today as the most valuable asset of any organisation, and in a rapidly growing world as ours, the key to success is not perceived anymore as money, but mainly as knowledge. Construction is not different, where knowledge plays a vital role in its projects success, construction design phase in particular is one of the highest activities in terms of knowledge generation, however, designers still have got no clear process to manage knowledge efficiently. On the other hand, BIM or Building Information Modeling; a revolutionary framework that invaded construction market through the last decade, has a fundamental effect over the whole industry and over the way of how things are done, therefore, among the hundreds of applications and benefits of BIM, knowledge management could be one of them. This Paper attempts to fill that gap, by suggesting the use of BIM as a powerful tool to manage knowledge efficiently within the construction design activities to help in finally overcoming all limitations of the previous traditional knowledge management models, this is done through proposing a conceptual model that adds knowledge as an extra dimension to BIM, and which can capture knowledge generated during projects, assign it to the corresponding model building components, using the BIM parametric option, where it can be shared and easily recovered later when needed. New definitions are introduced through this paper and an illustrative hypothetical case study is conducted by the end of the study, to validate the proposed framework and demonstrate its effectiveness, benefits and expected limitations.
\end{abstract}

(c) 2020 The Authors. Published by Budapest University of Technology and Economics \& Diamond Congress Ltd Peer-review under responsibility of the Scientific Committee of the Creative Construction Conference 2020.

Keywords: BIM; knowledge management; construction design

\section{Introduction}

Knowledge has been always perceived in the past and the present as one of the most important resources of any organisation, twenty years ago, Stewart and Ruckdeschel (1998) stated that "Knowledge has become the most important asset of companies", while after the world economic crisis in 2008 and then the Oil prices drop in the Middle East in 2015, the importance of knowledge grew more significantly and became obviously the key to organisational excellence. Literature has always been highlighting the importance of knowledge, where many researchers and authors have concluded a direct relation between knowledge and attaining competitiveness, survival and success (Deshpande et al., 2014, Egbu, 2004 and Quintas, P. 2005). Knowledge basically refers to the awareness, understanding and experience gained and accumulated by time, it involves best practices, lessons learned and gained skills. A decision made based on effective knowledge can save a lot of time and money, and that what urged different organisations to start investing in knowledge management. On the other hand, Knowledge management refers to any process that aims to save knowledge from being lost, the Online Business Dictionary defined knowledge management as "the 
strategies and processes designed to identify, capture, structure, value, leverage and share organisational intellectual assets to enhance it's performance and competitiveness", similar meanings and definitions for knowledge management were discussed by studies in the past (Lin, Y.,2005, Davenport and Prusak, 2000, Tan, H., 2010, Bhatt, G., 2001) most of them have agreed that knowledge management is all about a group of processes that aims to manage and make the best use out of gained knowledge, common processes include: knowledge capture, knowledge sharing, knowledge maintenance and knowledge reuse.

Moving to Construction industry, where no project looks like the other and only few or negligible similarities exist, as each project has got its unique needs, challenges and circumstances (Boyd, 2013), each construction project generate its own knowledge and lessons learned. Moreover, construction is widely known for its fragmented and diverse nature, due to the participation of various stakeholders from different backgrounds, also Olawale, Y. and Sun, M. (2015) added that construction activities are characterised by its high creativity and dynamism. All of these facts make construction one of the most knowledge-intensive industries in the world market, and gives the area of knowledge management a vital importance. However, Knowledge management is still suffering within the construction fields, and is not being adequately addressed by researchers or considered by industry members, this led to a negative impact over the efficiency of the construction output, where the industry became famous for being an environment of repeated mistakes, wasted time, over-budget and never-achieved quality.

When splitting the construction project life cycle into two main phases; site and off-site, clearly, most of the research effort was focused on the 'site' project activities when examining knowledge management, while keeping the 'off-site' phase which mainly refers to the design stage, lacking the sufficient research and study needed to come out with innovative and efficient knowledge management solutions. Design stage is sometimes seen as the most essential part of any project due to the fact that critical decisions that can have a whole life impact over the project are being taken during this stage, and although the design has the lowest proportion of the project time and budget, but programme extensions and budget variations that take place during design may lead to a significant change in the whole project. Eastman, C. et al. (2011) have discussed how a lot of time and money are being wasted during construction design stages while preparing project documents as drawings, cost estimates and quantity schedules, where most of the wasted time and money could have been saved if lessons learned in the past were managed effectively.

On the other hand, over the recent years, Information technology or IT had broken into many industries leaving a huge impact over the profitability and success of organisations, Construction was not different, where IT had also emerged across it clearly, and on the top of its applications was Building Information Modeling or BIM, a totally new framework that is supposed to be integrated in the whole life cycle of construction projects, starting from design phase till the facility operation, aiming to attain a higher level of coordination and integration. Although BIM is still developing, but there are already enough BIM completed projects in the recent years worldwide that can enable us to determine how much BIM can improve the construction industry and the design activities in particular. BIM could clearly accelerate the completion of projects, lead to reduction in total costs, improve labor productivity and enhance the value and quality of design output.

Moreover, the rapid growth of BIM over the globe and its mandatory implementation in some countries motivates involving and utilising it in improving the construction off-site knowledge management. However, the process of integrating knowledge management and BIM during design is still far from being well explored compared to other benefits of BIM, and compared to other phases of construction. Some researchers have already attempted to approach this area, but most of them failed to offer an applicable model that could be developed and incorporated into the design phase daily activities to enhance the knowledge management environment significantly (Meadati et al., 2010, Wu, 2013, Deshpande et al., 2014, Amireddy, 2014, Fruchter et al., 2009)

This study is aiming to fill that gap, add to the previous research and contribute to solve the problem of inefficient knowledge management environment that construction design is suffering from, this will be done through proposing a model that integrates Knowledge management traditional principles with the growing contemporary BIM tools, and has the capability of capturing knowledge generated during projects 
design phases, categorise it, store it and make it recoverable for the future projects, in the fastest and most efficient possible route, making advantage of the already growing technologies of BIM worldwide.

\section{Methodology}

In order to achieve the research aim, which is formulating a conceptual model that can enhance the knowledge management environment within the construction design phase through using BIM tools, the paper adopted a road map that consists of four steps; First, introduction to the new concept of a Building Knowledge Modeling (BKM) which is developed out from the Building Information Modeling (BIM), Second; Categorisation of design knowledge into specific number of categories so they can be easily managed within the model, Third, introduction to the three pillars of the proposed model, which are BKM Parameters, BKM Library and BKM clash detection system, Finally; the paper presents a hypothetical case simple project to validate the proposed framework and gives a better understanding to the reader.

\section{Building Knowledge Modeling}

Building Information Modeling is known for its capability to include an unlimited number of dimensions, where the 3D model for instance can be developed to a 4D model by adding time dimension, or to a 5D model by adding cost dimension, and recently, researches have discussed new dimensions as the 6D for sustainability, 7D for facility management, and more dimensions are still on their way. The Concept of Building Knowledge Modeling (BKM) can simply refer to adding Knowledge as a new dimension to BIM Models, where knowledge management principles are integrated with BIM tools to formulate a model that can help in managing knowledge in the design fields.

Although the BKM Concept is still a newly introduced topic, but it has been slightly approached by few studies over the last couple of years. Almost ten years ago, authors started to suggest the integration between Knowledge and BIM (Fruchter et al., 2009, Meadati et al., 2010). Five years later, Wu (2013) introduced the first conceptual applicable BKM model through proposing an HTTP development that is able to send lessons learned from BIM users to a knowledge repository, the paper was a positive contribution and a step further to the development of BKM, however it was still seen as a raw approach that lacked technical details or practical validation. One year later, three more major studies in the field were introduced (Deshpande et al., 2014, Amireddy, 2014, Lin, 2014) where the authors started to put the BKM concept into the real life context and design applicable conceptions.

Any Building component inside a BIM model should have non-graphical information attached to its 3D geometry, while in the proposed BKM model, the component should have one more attachment, which is knowledge. Table (1) is an attempt to illustrate the differences between various building components in the ordinary CAD (Computer Aided Design), current BIM (Building Information Model) and the proposed BKM (Building Knowledge Model), in terms of the data that can be extracted from the model in each case.

Table 1. Comparison between CAD, BIM and BKM in terms of attached data

\begin{tabular}{llll} 
Building Component & CAD & BIM & BKM \\
\hline Definition & $2 \mathrm{D}+3 \mathrm{D}$ & 2D +3D + Information & 2D + 3D + Information + Knowledge \\
A Door & $\begin{array}{l}\text { Geometrical } \\
\text { Dimensions }\end{array}$ & Information; Manufacturer & Knowledge; End User feedback \\
A Column & $\begin{array}{l}\text { Geometrical } \\
\text { Dimensions }\end{array}$ & Information; Load & Knowledge; Structural Standards \\
An Air Conditioning Unit & $\begin{array}{l}\text { Geometrical } \\
\text { Dimensions }\end{array}$ & Information; Power & Knowledge; Installation User Manual \\
A Lighting Unit & $\begin{array}{l}\text { Geometrical } \\
\text { Dimensions }\end{array}$ & Information; Wattage & Knowledge; Supplier Guidelines
\end{tabular}


An Architectural building component as a simple door, was viewed only as a geometrical component within the basic CAD environment, where data as the door width and door height were the only kind of information that could be extracted, after the emersion of BIM, other types of information could be extracted, as the manufacturer details, fire rating, finish material, colour, cost and hundreds of other related data, while if the proposed BKM concept is implemented, it means that knowledge will be also available and attached to each building component (eg. a door), the "end user feedback" or how the users have reported and evaluated the door after usage, is a clear example for the type of knowledge that can be available, but then, this leaves us in front of a vital and important question, what are the categories to be considered as knowledge in the construction design environment?

\subsection{Design knowledge categories}

In order to formulate a BKM conceptual model that can manage design knowledge, there was a strong need to categorise knowledge within the design field. There had been always attempts to categorise and classify knowledge through previous literature, some authors divided knowledge into explicit and tacit (X. Zhang et al., 2009) where explicit refers to the part of knowledge that can be easily written and recorded in documents, while the tacit is the knowledge gained through experience and may not be recorded in documents. Others classified knowledge into Passive and Active (Boyd, 2013) where the passive knowledge is the part related to the way of thinking, while the active is related to the way of doing tasks, similarly Tan H. et al. (2007) divided knowledge into General, specific and process. However, there was almost a negligible effort made to categorise design knowledge.

Interviewing was found to be an effective method to explore the different types of knowledge within design organisations, due to the deep and detail access to human experience and impression that it can allow during the interviewing, moreover, interviews allows the discussion to be directed in a way that serves the aim of the research. The Interview design was based on its purpose, first the interviewee receives an introduction to knowledge and its importance in the field of construction design, then, he or she is requested to list few examples of knowledge from his or her experience in the field. Five interviewees were selected, based on the accessibility, willingness to help, and mainly the extent of how much he or she are involved in the design process and have an interest to improve it.

Interviewee \#1 was a 43 years old consultancy general director, when asked about types of knowledge within the design field, he stated that 'Data about the different clients in the market is considered to be a very essential and valuable part of knowledge, each major client in the market has got their own values, priorities, criteria and requirements, such type of knowledge can only be gained through lots of effort and over many years, and most probably it gets lost" Interviewee \#2, a project design manager, narrated an incident that took place during one of his projects, and which highlights one of the most important type of knowledge in the design work, 'after we have fully completed the design of a warehouse facility project whose main function was to store sensitive documents, and while we were finalising the design documents, we have discovered that we missed an important stamp for such types of projects, the National Archive Authority Approval for the design, a public authority that should have been get involved in the early stages of design, but we missed it, I personally had never heard about it at that time, if we knew about it, we would have saved a lot of wasted time, money and effort". Therefore, local permits, design review reports and authorities' approvals can all be considered as an important part of design knowledge that only comes with experience. Interviewee \#3 believed that all the problems solved, lessons learned and best practices found during design activities, technical processes and business meetings, in addition to the feedback of the end users of the designed facilities, all represents the real core of design knowledge. While Interviewee \#4 argued that 'International design standards' type of knowledge, are seen to be the most part of design activities consuming time and effort and which needs to be stored efficiently somewhere. Finally, the last interviewee, being an architect, claimed that design contextual knowledge, is a very essential subject, where designers spend a lot of time in researching, surveying and studying in order to have access to such knowledge. Table (2) shows a summary of the Interviewees details and their corresponding answers: 
Table 2. Interviewees details and answers

\begin{tabular}{llll}
\hline$\#$ & Professional Title & Experience & Knowledge Examples provided \\
\hline 1 & Consultancy Director & 43 years & Client Knowledge \\
2 & Project Manager & 24 years & Permits and Approvals \\
3 & Design Lead & 7 years & Problems solved and Lessons Learned \\
4 & Architect & 8 years & Standards \\
5 & Architect & 27 years & Contextual Knowledge \\
\hline
\end{tabular}

As shown in Figure (1) and based on the interviews responses, the design knowledge could be classified into four major categories, that all relates directly to the design project.

First, the Client Knowledge, where there could be a database of different market clients and organisations, showing their priorities, evaluation criteria, values, needs and policies of each client, in addition to the details of the key personnels of each organisation, such type of knowledge could save a lot of time wasted by designers in knowing more about their clients, whereas this time could have been utilised in satisfying the client needs and design requirements. Second, the Context Knowledge, and this

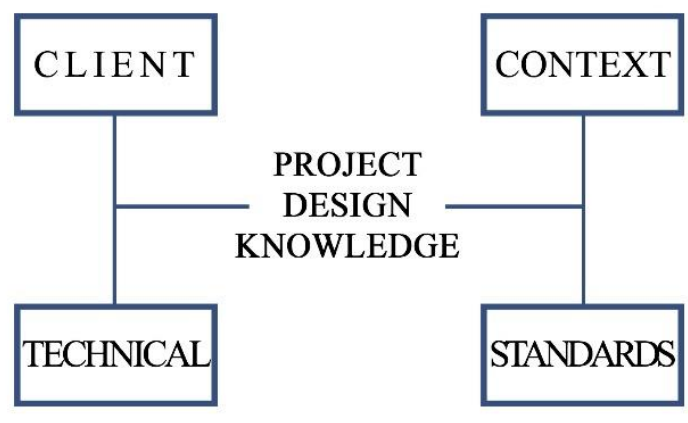
is the part of knowledge that is related to the place where the project takes place, as the project location is directly impacting its design, a database that consists of architectural styles, urban patterns, infrastructure networks, governmental legislations, municipal regulations and many other aspects, could be formulated, and knowledge would be classified according to different cities and regions of the world, to provide designers with the needed contextual information based on the location of their project. Third, Technical Knowledge, which refers to all the technical aspects of the design teams, and represented by a knowledge library that include solutions to problems that have been solved before, best practices that had been proven to be efficient in the past, lessons learned and also all the feedback of all the design process members, as architects, designers, managers and even end users. Finally, the Fourth category of design knowledge is the Standards Knowledge and this refers to all types if design standards, which represent a major controller of the design process, this may include architectural standards, structural standards, health and safety standards, local or international. 


\subsection{BIM knowledge parameters}

Knowledge categorisation made through the previous section makes it easier now to move to next step and integrate knowledge in a BIM model, but to do so, 'Parametric option' of BIM should be introduced first.

Parametric option is a unique characteristic of BIM models and which makes it different from normal CAD drawings, where $\quad C A D$ building components are only geometry, while the BIM building components have got parameters attached to the geometry, BIM parameters are placeholders for information, and each parameter should be defined by descriptive titles. Figure (2) shows the information Parameters of a Door type, in 'Autodesk Revit', a widely used BIM authoring software, as clearly shown, each parameter has got a descriptive title (eg. Width, Height, Tolerance, Keynote, etc..) and each parameter title has got a corresponding value. Moreover, it can be noticed that the parameters are categorised, where each group of similar parameters are placed together under one head title, (eg. Dimensions, Materials, Identity, Other, etc...)

Based on Knowledge categories proposed in this study and using the parametric categorisation set in 'Autodesk Revit', knowledge can then become attached easily to different building components inside a BIM model, and this can be achieved by setting up five categories of Knowledge parameters (Client, Context, Technical, Standards and Other), where each category comprises set of different parameters, ready to store knowledge and share it with designers who use the same building component. Figure (3) shows the two types of BIM parameters, the existing information parameters, and the proposed knowledge parameters, with few examples for each parameter category for a better understanding. 


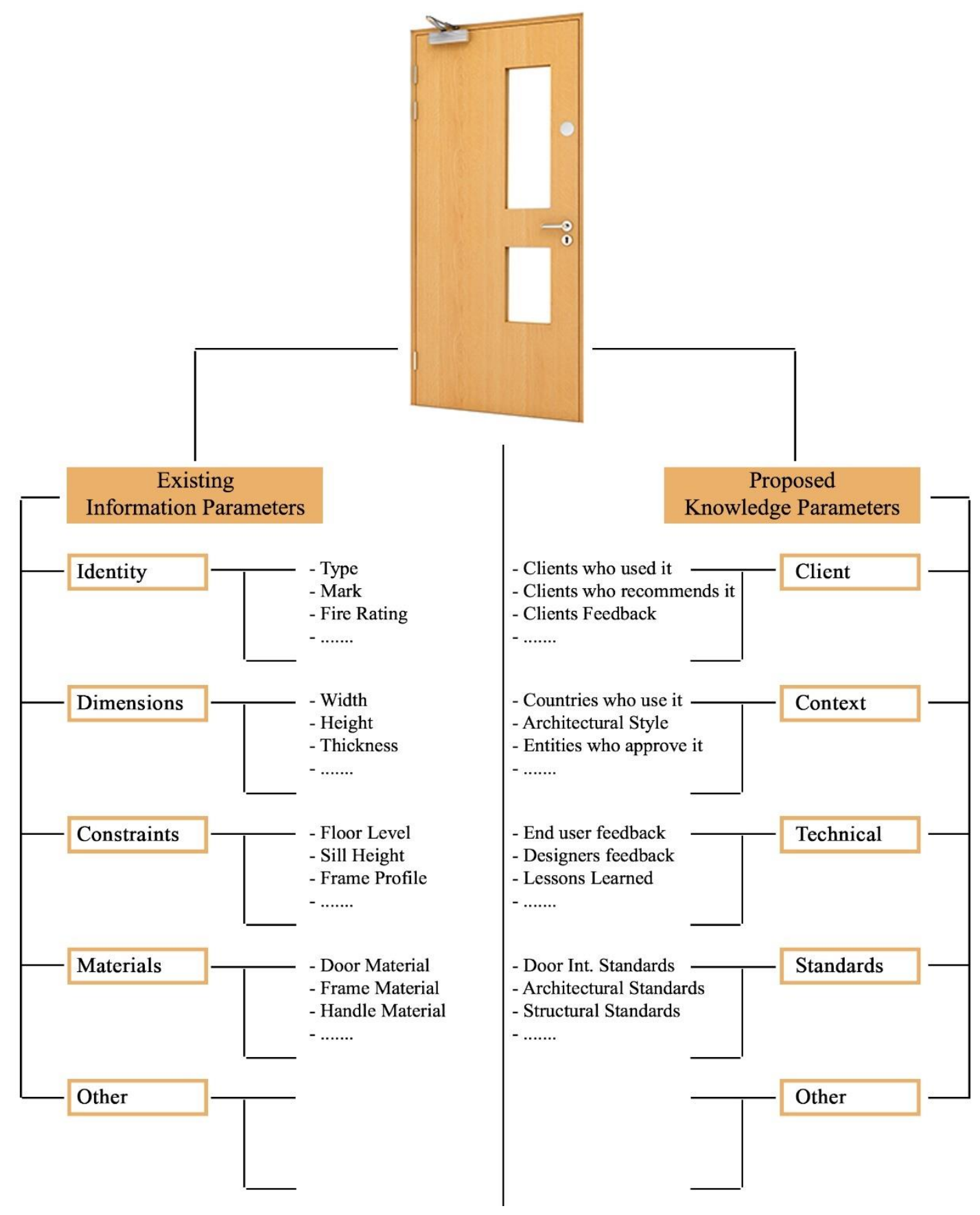




\subsection{Building Knowledge Modeling (BKM) Library}

One of the key features of BIM is the online library, where different members of the industry (eg. designers, suppliers, manufacturers) anywhere could create a unique building component and share it with the rest of the world, for example, Philips Lighting International, the Dutch technology company, created all of its products in the form of BIM digital components in Autodesk Revit file format, and share it via its online website, these components contain all the necessary information parameters and properties as per Philips product standards (eg. dimensions, light colour, light intensity, model name, etc..), so designers could make use of them.

This takes us to the concept of developing a Building knowledge modeling (BKM) library, a library that has a similar approach to the existing BIM online library, but with knowledge stored instead of information, an online global repository that is able to receive knowledge from all members of the industry (eg. designers, clients, suppliers, contractors, etc..), maintain and categorise it based on the knowledge categorisation technique, share it with the world, and keep it available for the future reuse of designers through their BIM models.

As the case of the BIM library, a BKM Library develops itself by time, where the more input it gets in from different industry members, the more useful it becomes to designers, Figure (4) shows the two types of BIM libraries to be available for the designers.

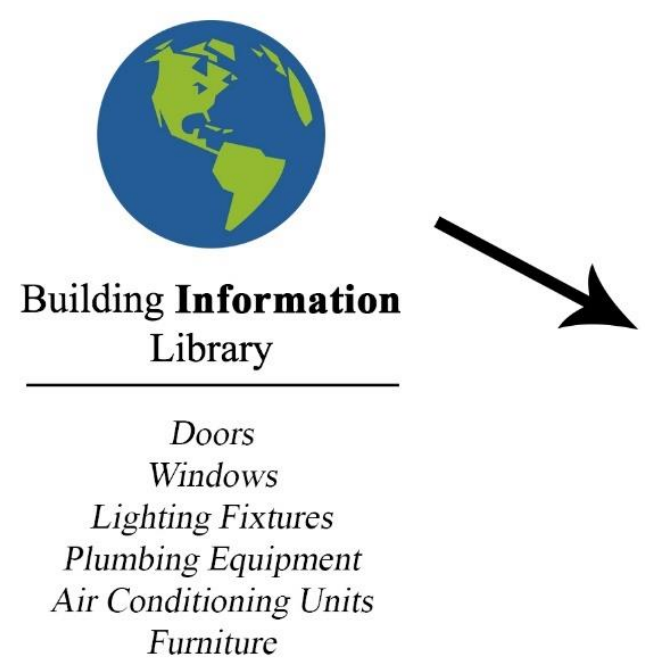

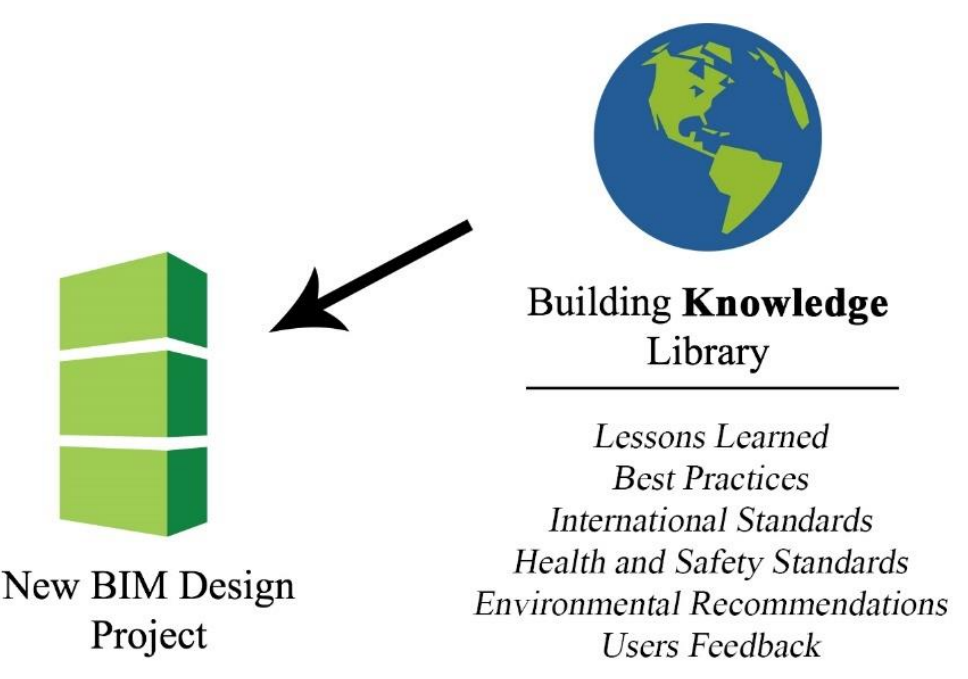

Building Knowledge

Library

Lessons Learned

Best Practices

International Standards

Health and Safety Standards

Users Feedback

\subsection{Knowledge clash detection}

One more major benefit of BIM is clash detection, clash within design refers to the case when project components are not spatially coordinated, whether two or more components are occupying the same space, or even a component is not given the spatial tolerance it requires to be installed or maintained. BIM provide designers with the ability to spot clashes at an early stage, where they should be much easier, cheaper and time saving to rectify at that stage than

\begin{tabular}{l} 
Technical Knowledge Compatible \\
\hline Client Knowledge Clash Detected \\
\hline Context Knowledge Compatible \\
\hline Standards Knowledge Compatible
\end{tabular}
in site.

Using the previous findings and proposals discussed in this study, BIM could also be utilised to find out knowledge clashes, where developed tools and software can have the potential to carry out a compatibility test, where it compares the design with the verified and trusted knowledge stored within the BKM library, and automatically detect clashes between the design parameters and knowledge if found, as when in Figure 
(5), and it instantly inform the design team with the clashes, and could also contribute to resolving them by suggesting solutions based on the database of similar problems solved in the past and was stored to the BKM library, the design team will then face three different options, first, to find the perfect solution for resolving the clash, second, find a solution that needs some more work to make it fit, or finally to find no solutions where they will have to propose their own, the reaction of the design team to each of the three options ensure a continuous

development and validation to the global BKM library, the reactions are shown in Figure (6).
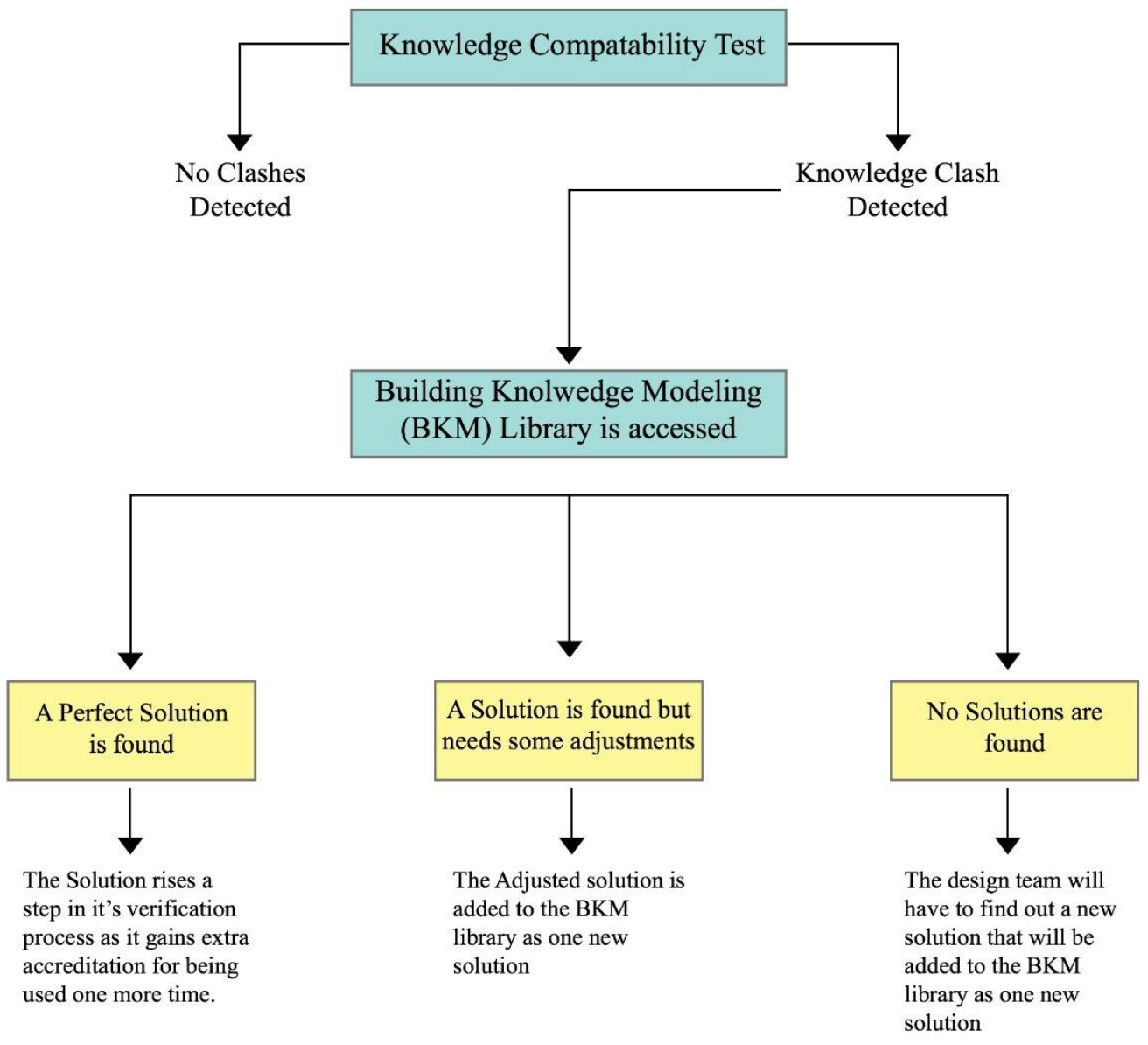

\section{Case study application}

In order to give a better understanding for the proposed conceptual model, a hypothetical design project is given in the following part of the study, to show clearly how such a model could be applied. The Project details are as follows:

Location: London, UK

Client: Bank of England

Project: Design of a 20 storeys Administrative building

\section{Building Component to be examined: Building Main Entrance Door}

It is the responsibility of the design team to fill the Building Information Model for the project with the details parameters mentioned above since day one, once the project details are entered, the model should be able to search into specific areas of the BKM library. For instance, regarding to Context knowledge, the model should refer only to all projects completed in London, make sure the selected door is available in UK, could be supplied, manufactured or even imported, it also could confirm if it has been used in UK before, or if it has been approved by a British entity.

Moving to the Client knowledge, the model will look for all projects owned by the Bank of England, and check weather that type of doors had been used before or not within their projects, and if yes, what was their feedback. 
On the other hand, in the Standards knowledge area, the model should refer to British, European as well as the International standards of doors design, and make sure that the design parameters made by the design team is compatible with all the standards, (eg. dimensions, material, use, etc...)

Finally, Technical knowledge, where the model will look in every piece of knowledge related to Doors, including lessons learned from those who used that type of doors in the past, weather designers, suppliers or even end-users, in addition to best practices, installation guidelines, design recommendations and many other knowledge parameters, that should grow and develop by time.

After the design is completed, a Compatibility test similar to what is shown in Figure (5) is made, where clashes will be spotted, and a group of solutions to resolve those clashes will be offered based on the Knowledge extracted from the BKM library, for the design team further action.

\section{Conclusion}

Despite the rapid growth and development of the Construction industry all over the world, this paper highlighted a gap found in the design phase of construction, the lack of an efficient knowledge management framework to manage the lots of knowledge lost during design activities and projects. The study proposed utilising and exploiting BIM as an existing growing technology in filling that gap, through adding one more dimension to the Building information models, which is Knowledge, thus open the doors for a new generation of BIM uses and definitions. Adopting the concept of BKM the paper has introduced a group of new definitions which act as the main aspects of the proposed model (eg. BKM Parameters, BKM Library and BKM Clash detection system).

The Proposed model shows a promising ability to aid in improving the knowledge management environment within the construction design phase, knowledge will be stored and maintained, it will also be available for reuse in future design projects, the model has also got the ability to develop and update itself continuously through time.

Future Research may consider developing a sophisticated software tool or a plugin that can transform this proposed conceptual model into a real application that can be incorporated into a BIM common platform, also future studies may include adding more categories of design knowledge beside the four categories proposed in this paper, or classifying those four titles into detailed subtitles, this would enrich the model and enhance the general process of knowledge management.

\section{References}

[1] Amireddy, S., 2014. Knowledge management in construction using building information modeling (BIM) (Doctoral dissertation).

[2] Bhatt, G.D., 2001. Knowledge management in organizations: examining the interaction between technologies, techniques, and people. Journal of knowledge management. https://doi.org/10.1108/13673270110384419

[3] Boyd, D., 2013. Using events to connect thinking and doing in knowledge management. Construction Management and Economics, 31(11), pp.1144-1159. https://doi.org/10.1080/01446193.2013.866260

[4] Davenport, T.H. and Prusak, L., 2000. Working knowledge: How organizations manage what they know. Ubiquity, 2000 (August), p.6. https://doi.org/10.1145/347634.348775

[5] Deshpande, A., Azhar, S. and Amireddy, S., 2014. A framework for a BIM-based knowledge management system. Procedia Engineering, 85, pp.113-122. https://doi.org/10.1016/j.proeng.2014.10.535

[6] Eastman, C.M., Eastman, C., Teicholz, P., Sacks, R. and Liston, K., 2011. BIM handbook: A guide to building information modeling for owners, managers, designers, engineers and contractors. John Wiley \& Sons. https://doi.org/10.1002/9781119287568

[7] Egbu, C., Kurul, E., Quintas, P., Hutchinson, V., Al-Ghassani, C.A.A., Ruikar, K. and Consultancy, A.M.D.L., 2003. Techniques and technologies for knowledge management work package 3-interim report. Innovation, 101(39/3), p.709. https://doi.org/10.1002/9780470759554.ch6

[8] Fruchter, R., Schrotenboer, T. and Luth, G.P., 2009. From building information model to building knowledge model. In Computing in Civil Engineering (2009) (pp. 380-389). https://doi.org/10.1061/41052(346)38

[9] Lin, Y.C., 2014. Construction 3D BIM-based knowledge management system: a case study. Journal of Civil Engineering and Management, 20(2), pp.186-200. https://doi.org/10.3846/13923730.2013.801887

[10] Lin, Y.C., Wang, L.C., Tserng, H.P. and Jan, S.H., 2005. Enhancing knowledge and experience exchange through construction mapbased knowledge management system. In Construction Research Congress 2005: Broadening Perspectives (pp. 1-10). https://doi.org/10.1061/40754(183)84

[11] Meadati, P. and Irizarry, J., 2010, April. BIM-a knowledge repository. In Proceedings of the 46th Annual International Conference of the Associated Schools of Construction (Vol. 12).

[12] Olawale, Y. and Sun, M., 2015. Construction project control in the UK: Current practice, existing problems and recommendations for future improvement. International journal of project management, 33(3), pp.623-637. https://doi.org/10.1016/j.ijproman.2014.10.003 
Proceedings of the Creative Construction e-Conference (2020) 068

Available online at e-2020.creative-construction-conference.com/proceedings/

[13] Quintas, P., 2005. The nature and dimensions of knowledge management. Knowledge management in construction, pp.10-30. https://doi.org/10.1002/9780470759554.ch2

[14] Stewart, T.A., 2010. Intellectual Capital: The new wealth of organization. Currency. https://doi.org/10.1108/lodj.1999.20.6.337.1

[15] Tan, H.C., Carrillo, P.M., Anumba, C.J., Bouchlaghem, N., Kamara, J.M. and Udeaja, C.E., 2007. Development of a methodology for live capture and reuse of project knowledge in construction. Journal of management in engineering, 23(1), pp.18-26. https://doi.org/10.1061/(asce)0742-597x(2007)23:1(18)

[16] Tan, H.C., Carrillo, P.M., Anumba, C.J., Bouchlaghem, N., Kamara, J.M. and Udeaja, C.E., 2007. Development of a methodology for live capture and reuse of project knowledge in construction. Journal of management in engineering, 23(1), pp.18-26. https://doi.org/10.1002/9781444315448

[17] Wu, D., 2013. Building knowledge modeling: Integrating knowledge in BIM. In Proceedings of the 30th International Conference of CIB W078, Beijing, 9-12 October.

[18] Zhang, X., Mao, X. and AbouRizk, S.M., 2009. Developing a knowledge management system for improved value engineering practices in the construction industry. Automation in construction, 18(6), pp.777-789. https://doi.org/10.1016/j.autcon.2009.03.004 